\title{
Supporting Information: Disentangling the Physical Processes Responsible for the Kinetic Complexity in Interfacial Electron Transfer of Excited Ru(II) Polypyridyl Dyes on $\mathrm{TiO}_{2}$
}

David F. Zigler, Zachary A. Morseth, Li Wang, Dennis L. Ashford, M. Kyle Brennaman, Erik M. Grumstrup, Erinn C. Brigham, Melissa K. Gish, Robert J. Dillon, Leila Alibabaei, Gerald J. Meyer, Thomas J. Meyer, and John M. Papanikolas*

University of North Carolina at Chapel Hill, Caudill, Kenan and Murray Laboratories, Department of Chemistry, CB\#3290, Chapel Hill, NC 27599, U.S.A.

\section{Contents}

\begin{tabular}{llc}
\hline \multicolumn{1}{c}{ Section } & \multicolumn{1}{c}{ sub-Section } & Page \\
\hline I. Experimental & A. Electronic Absorption & S2 \\
& B. Photoluminescence & S2 \\
& C. Electrochemistry & S2 \\
& D. Spectroelectrochemistry & S3 \\
& E. Transient Absorption Spectroscopy & S3 \\
& F. Computational Methods & S3 \\
II. Supporting & A. Time-Resolved Spectroscopy & S3 \\
Results and & B. Comparison of Biexponential versus Kohlraush-Williams- & S4 \\
Discussion & Watts fits to decay data & S5 \\
& C. Static Spectroscopy (Ground state absorption spectra, & S8 \\
& D. Solution Electrochemistry & S10 \\
& E. Frontier orbitals from DFT calculations & S11 \\
& F. Spectroelectrochemistry determination of TiO 2 density of & S13 \\
& G. Picosecond Evolution on the Surface & S14 \\
& H. Kinetic Model and Derivation of Integrated Rate Law & S17
\end{tabular}




\section{EXPERIMENTAL}

Materials: The ruthenium dyes used for this study are presented in Figure 1 in the main text. The synthesis and characterization of the complexes $\left[\mathrm{Ru}(\mathrm{bpyP})(\mathrm{bpy})_{2}\right] \mathrm{Cl}_{2}(\mathbf{P}),\left[\mathrm{Ru}(\mathrm{bpyP})_{2}(\mathrm{bpy})\right] \mathrm{Cl}_{2}$, (P2), $\left[\mathrm{Ru}(\mathrm{bpyP})_{3}\right] \mathrm{Cl}_{2} \quad$ (P3), $\quad\left[\mathrm{Ru}(\mathrm{bpyP})(\mathrm{dBrb})_{2}\right] \mathrm{Cl}_{2} \quad$ (P-dBrb), $\left[\mathrm{Ru}(\mathrm{bpyP})(\mathrm{dMeOb})_{2}\right] \mathrm{Cl}_{2} \quad$ (PMeOb), $\left[\mathrm{Ru}(\mathrm{bpyP})(\mathrm{dmb})_{2}\right] \mathrm{Cl}_{2}$ (P-dmb), $\left[\mathrm{Ru}(\mathrm{bpyCP})(\mathrm{bpy})_{2}\right] \mathrm{Cl}_{2}$ (CP), $\left[\mathrm{Ru}(\mathrm{bpyCP})_{2}(\mathrm{bpy})\right] \mathrm{Cl}_{2}$ $(\mathbf{C P 2})$, and $\left[\mathrm{Ru}(\mathrm{bpyCP})_{3}\right] \mathrm{Cl}_{2}(\mathbf{C P 3})$ have all been reported elsewhere, ${ }^{1,2}$ where bpy $=2,2^{\prime}-$ bipyridine, bpyP = 4,4'-bis(phosophonic acid)-2,2'-bipyridine, bpyCP = 4,4'bis(methylenephosophonic acid)-2,2'-bipyridine, $\mathrm{dBrb}=4,4$ '-dibromo-2,2'-bipyridine, $\mathrm{dMeOb}=$ 4,4'-dimethoxy-2,2'-bipyridine, and $\mathrm{dmb}=4,4$ '-dimethyl-2,2'-bipyridine. The complexes $\left[\mathrm{Ru}(\mathrm{bpyCP})(\mathrm{dBrb})_{2}\right] \mathrm{Cl}_{2} \quad(\mathbf{C P}-\mathbf{d B r b}), \quad\left[\mathrm{Ru}(\mathrm{bpyCP})\left(\mathrm{dMeOb}_{2}\right] \mathrm{Cl}_{2} \quad(\mathbf{C P}-\mathbf{d M e O b}), \quad\right.$ and $\left[\mathrm{Ru}(\mathrm{bpyCP})(\mathrm{dmb})_{2}\right] \mathrm{Cl}_{2}(\mathbf{C P}-\mathbf{d m b})$ were synthesized following procedures adapted from Ashford et al. ${ }^{1}$ Dye purity was confirmed with ${ }^{1} \mathrm{H}-\mathrm{NMR}(400 \mathrm{MHz})$. Water was HPLC grade (Fischer), and perchloric acid $\left(\mathrm{HClO}_{4}(a q), 70 \% \mathrm{v} / \mathrm{v}\right.$, Aldrich) was of the highest grade commercially available $(99.999+\%)$. Unless otherwise specified, all solution conditions in this study were aqueous perchloric acid at $\mathrm{pH}=1$. $\mathrm{TiO}_{2}$ or $\mathrm{ZrO}_{2}$ films on fluorine doped tin oxide glass (FTO) were prepared as previously described. ${ }^{3,4}$ Briefly, colloidal pastes of the appropriate precursor were doctor bladed onto the FTO glass, then calcined at $450^{\circ} \mathrm{C}$ or $400^{\circ} \mathrm{C}$ in air. Typical film thicknesses were between $2 \mu \mathrm{m}$ and $5 \mu \mathrm{m}$, as characterized by profilometry. Loading solutions were made by dissolving dye $(\sim 1 \mathrm{mM})$ in $0.1 \mathrm{M} \mathrm{HClO}_{4}(a q)$. Films were soaked in dye solution for 24 hours and transferred to fresh $0.1 \mathrm{M} \mathrm{HClO}_{4}(a q)$ to remove extraneous dye. The $0.1 \mathrm{M}$ $\mathrm{HClO}_{4}(a q)$ solution covering the dyed slides was exchanged at least once. Slides were stored in $0.1 \mathrm{M} \mathrm{HClO}_{4}(a q)$ in the dark with no observed change to the kinetics or absorption spectra over several months.

A. Electronic Absorption: Electronic absorption spectra were obtained using an Agilent 8453 photo-diode array UV-visible spectrophotometer.

B. Photoluminescence: All photoluminescence spectra were acquired on a PTI Quantamaster 4SE-NIR5, equipped with real time excitation correction and controlled using FeliX32 software package from PTI and spectra were corrected for instrument spectral response (Hammamatsu 928 photomultiplier tube). All were excited with $450( \pm 2) \mathrm{nm}$ light and detected at $90^{\circ}$ to the excitation path with spectral resolution ranging from 0.5 to $1 \mathrm{~nm}$. Samples in solution were made to have an absorbance of $0.4(1 \mathrm{~cm})$ at the excitation wavelength. Samples of dye on $\mathrm{ZrO}_{2}$ were held at $45^{\circ}$ to the excitation source using a custom cuvette with PTFE positioner. All samples were deoxygenated by flowing ultra-high purity argon for $1 \mathrm{hr}$ prior to acquiring the photoluminescence.

C. Electrochemistry: Electrochemical measurements of $\mathrm{TiO}_{2}$ bound dyes in $0.1 \mathrm{M} \mathrm{HClO}_{4}(a q)$ were performed using a $\mathrm{CH}$ Instruments 660D potentiostat with glassy carbon auxillary electrode and $\mathrm{Ag} / \mathrm{AgCl}(3 \mathrm{M} \mathrm{NaCl})$ reference electrode. The reference electrode was calibrated against an $\mathrm{SCE}(0.241 \mathrm{~V} \text { vs. NHE })^{5}$ and also the Ru(III/II) couple of $\left[\mathrm{Ru}(\mathrm{bpy})_{3}\right]^{2+}\left(1.26 \mathrm{~V}\right.$ vs. NHE). ${ }^{6}$ The $E^{\circ}$ values for each chromophore were taken from their peak potentials in square-wave voltammetry. These potentials matched well with the $E_{1 / 2}$ observed in the oxidative cyclic voltamograms with scan rate $(v)$ of $100 \mathrm{mV} / \mathrm{s}$. Electrochemistry conditions were reported previously for some of the dyes studied here, ${ }^{1,2,7}$ and the new dyes were studied in solution using the same. ${ }^{1}$ 
D. Spectroelectrochemistry: Spectroelectrochemistry was performed following literature adapted procedures ${ }^{8}$ to measure the density of states in the nanoparticle $\mathrm{TiO}_{2}$ films under conditions similar to the TA experiments. A dyed film $\left(5 \mu \mathrm{m} \mathrm{TiO}_{2}\right.$, ca. $\left.40 \% \mathrm{v} / \mathrm{v}\right)$ on FTO glass in a custom built spectroelectrochemical cell containing $0.1 \mathrm{M} \mathrm{HClO}_{4}(a q)$ was purged with argon. Potentials were applied using a BASi-50W potentiostat with the film as the working electrode, and using a glassy carbon auxillary and $\mathrm{Ag} / \mathrm{AgCl}$ reference electrode (Pine Research Instrumentation, Model\#: RRPEAGCL2). The applied potentials were calibrated against the $\mathrm{Ru}(\mathrm{III} / \mathrm{II})$ couple of the attached dye. Starting at $+100 \mathrm{mV}$ vs. NHE, potentials were swept at $-10 \mathrm{mV} / \mathrm{s}$ until the desired potential was reached, and then held until the absorption spectrum stopped changing. The reversibility was assessed by stepping the potential in the positive direction.

E. Transient absorption spectroscopy: Transient absorption experiments were performed using recently reported procedures. ${ }^{3,9,10}$ Briefly, pump and probe beams were derived from the output of a pulsed, amplified laser (Clark MXR CPA-2210 or CPA-2001, $1 \mathrm{kHz}, 775 \mathrm{~nm}$, p.w. $=200$ fs). A portion of the output was used to pump either a home built optical parametric amplifier (OPA) or TOPAS-C OPA (Light Conversion). Signal from the OPA was recombined in a BBO crystal with fundamental to create the tunable pump beam by sum-frequency generation. The pump beam was attenuated to $\leq 100 \mathrm{~nJ} /$ pulse with neutral density filters. Synchronously chopping the pump light at $500 \mathrm{~Hz}$ generated sequential pump on/off cycles. The remaining 775 $\mathrm{nm}$ fundamental was used to generate white light continuum probe in a $\mathrm{CaF}_{2}$ window. Chirp in the continuum was characterized using frequency resolved optical gating. Chirp correction was applied using a custom LabView program after fitting the cross correlation of the pump and probe pulses to a polynomial function. ${ }^{11}$ The pump (magic angle) and probe were delayed relative to each other using a mechanical translation stage. Each was focused to ca. $150 \mu \mathrm{m}$ within the sample. The pump beam was defocused to be slightly larger than the probe. Spectra were obtained using a high-speed camera detector and collected using a custom LabView program. The dyed $\mathrm{TiO}_{2}$ films were immersed in argon deoxygenated $0.1 \mathrm{M} \mathrm{HClO}_{4}(a q)$ and laterally translated. For each of a minimum of 6 slide samples per dye, 6000 to 12000 spectra were averaged at each time-point.

F. Computational Methods: Density functional theory calculations were performed with the Gaussian 09 program package ${ }^{12}$ with Becke's three parameter hybrid functional and Lee-YangParr's gradient corrected correlation functional (B3LYP). The LANL2DZ basis set and effective core potential were used for the $\mathrm{Ru}$ atom, while the $6-31 \mathrm{G}^{* *}$ basis set was applied to the $\mathrm{H}, \mathrm{C}$, $\mathrm{N}, \mathrm{O}, \mathrm{P}$, and $\mathrm{Br}$ atoms (where applicable). Solvation effects were included by modeling the solvent as a polarizable continuum model (PCM), as implemented in Gausian 09.

\section{SUPPORTING RESULTS AND DISCUSSION}

\section{A. Time-Resolved Spectroscopy}

The spectra of the $\mathrm{Ru}(\mathrm{II})$-dyes showed differences in width and positions of the bleach features when bound on $\mathrm{ZrO}_{2}$ and $\mathrm{TiO}_{2}$. The magnitude of these differences varies from one dye to the next. The $\mathbf{P}$ dye, for example, shows a large spectral shift between $\mathrm{ZrO}_{2}$ and $\mathrm{TiO}_{2}$ (Figure 3), but the CP-dmb has nearly coincident bleach features (Figure S1). The increase in 
the spectral width that is observed on $\mathrm{TiO}_{2}$ is consistent with loss of the $\mathrm{Ru}(\mathrm{II})^{*}$ excited state absorptions upon formation of the oxidized dye.

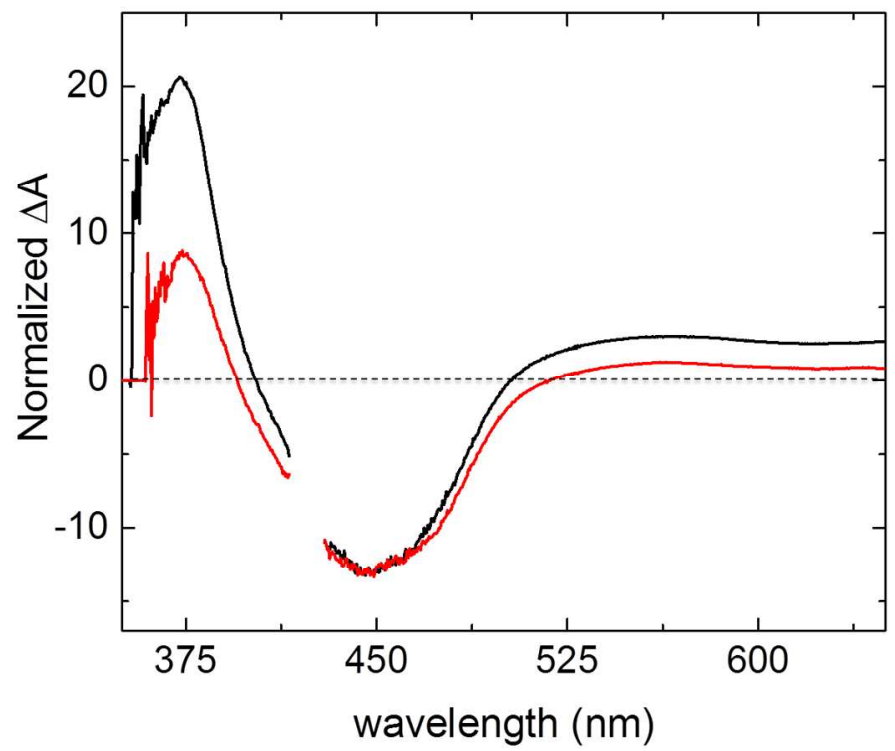

Figure S1. Comparison of CP-dmb transient spectra on $\mathrm{ZrO}_{2}$ and $\mathrm{TiO}_{2}$ obtained 6 ps following excitation at $420 \mathrm{~nm}$ (pump-scatter omitted for clarity).

\section{B. Comparison of Biexponential versus Kohlrausch-Williams-Watts fits to decay data}

A stretched exponential function, (i.e. $\left.\mathrm{I}(t)=A_{\mathrm{KWW}} \exp \left(-t / \tau_{\mathrm{KWW}}\right)^{\beta}\right)$, fits all the data sets reasonably well with a range of $\beta$-values from 0.4 to 0.6 . The residuals are comparable to those from the biexponential functions used in the manuscript, except at early times where the stretched exponential consistently overestimates the signal, and at long times where it underestimates the signal. In addition, whereas the amplitudes and time constants in the biexponential fit are correlated, no such correlation is present between $\beta$ and $\tau_{\mathrm{KWw}}$. Although the stretched exponential is a reasonable numerical model for the experimental data, the KWW function does not have a physical basis that can be used to develop a kinetic model. The difficulty with such thinking is that it ignores the experimental fact that this function fits a tremendous range of kinetic data even when it provides no reasonable underlying mechanistic insights. This flexibility of the KWW fitting function is in part due to correlations between $\beta$ and $\tau$. Indeed, Kohlrausch proposed the KWW equation empirically on the basis that it simply fit a vast amount of kinetic data. It is only since that time that derivations based on random walk models and serially-linked rate constants have appeared. In our opinion, it is not clear that the KWW model provides useful insights into the electron transfer processes in DSSCs, and for this reason we did not pursue its use in our analysis. Nevertheless, since the KWW function is ubiquitous in the analysis of injection/recombination data for molecular semiconductor systems, we have included a table of the fit values (Table S1) and a figure depicting a representative fit (Figure S2). 
Table S1. Time constants and amplitudes from stretched exponential fits to the decays probed at $376 \mathrm{~nm}$ in $0.1 \mathrm{M} \mathrm{HClO}_{4}(a q)^{a}$

\begin{tabular}{|c|c|c|c|}
\hline Dye & $\tau_{\mathrm{KWW}}(\mathrm{ps})$ & $A_{\mathrm{KWW}}$ & $\beta$ \\
\hline \multicolumn{4}{|c|}{ P-dRb series } \\
\hline P-dMeOb & $4.2( \pm 0.6)$ & $1.23( \pm 0.10)$ & $0.59( \pm 0.06)$ \\
\hline P-dmb & $7.5( \pm 0.8)$ & $1.33( \pm 0.06)$ & $0.50( \pm 0.03)$ \\
\hline $\mathbf{P}$ & $12.3( \pm 0.6)$ & $1.16( \pm 0.03)$ & $0.54( \pm 0.02)$ \\
\hline P-dBrb & $82( \pm 3)$ & $1.10( \pm 0.01)$ & $0.62( \pm 0.02)$ \\
\hline \multicolumn{4}{|c|}{ CP-dRb series } \\
\hline CP-dMeOb & $11.5( \pm 0.9)$ & $1.37( \pm 0.03)$ & $0.45( \pm 0.02)$ \\
\hline CP-dmb & $30( \pm 1)$ & $1.13( \pm 0.02)$ & $0.54( \pm 0.02)$ \\
\hline CP & $91( \pm 5)$ & $1.09( \pm 0.03)$ & $0.52( \pm 0.03)$ \\
\hline CP-dBrb & $271( \pm 58)$ & $1.16( \pm 0.09)$ & $0.54( \pm 0.04)$ \\
\hline \multicolumn{4}{|c|}{ Px series } \\
\hline $\mathbf{P}$ & $12.3( \pm 0.6)$ & $1.16( \pm 0.03)$ & $0.54( \pm 0.02)$ \\
\hline $\mathbf{P 2}$ & $23( \pm 2)$ & $1.10( \pm 0.03)$ & $0.59( \pm 0.04)$ \\
\hline $\mathbf{P 3}$ & $62( \pm 3)$ & $1.10( \pm 0.03)$ & $0.52( \pm 0.03)$ \\
\hline \multicolumn{4}{|c|}{ CPx series } \\
\hline $\mathbf{C P}$ & $91( \pm 5)$ & $1.09( \pm 0.03)$ & $0.52( \pm 0.03)$ \\
\hline CP2 & $39( \pm 2)$ & $1.22( \pm 0.02)$ & $0.44( \pm 0.01)$ \\
\hline CP3 & $19( \pm 2)$ & $1.32( \pm 0.05)$ & $0.59( \pm 0.06)$ \\
\hline
\end{tabular}

${ }^{a}$ At room temperature. Errors are from the non-linear least squares fit to the bin-averaged decay traces 


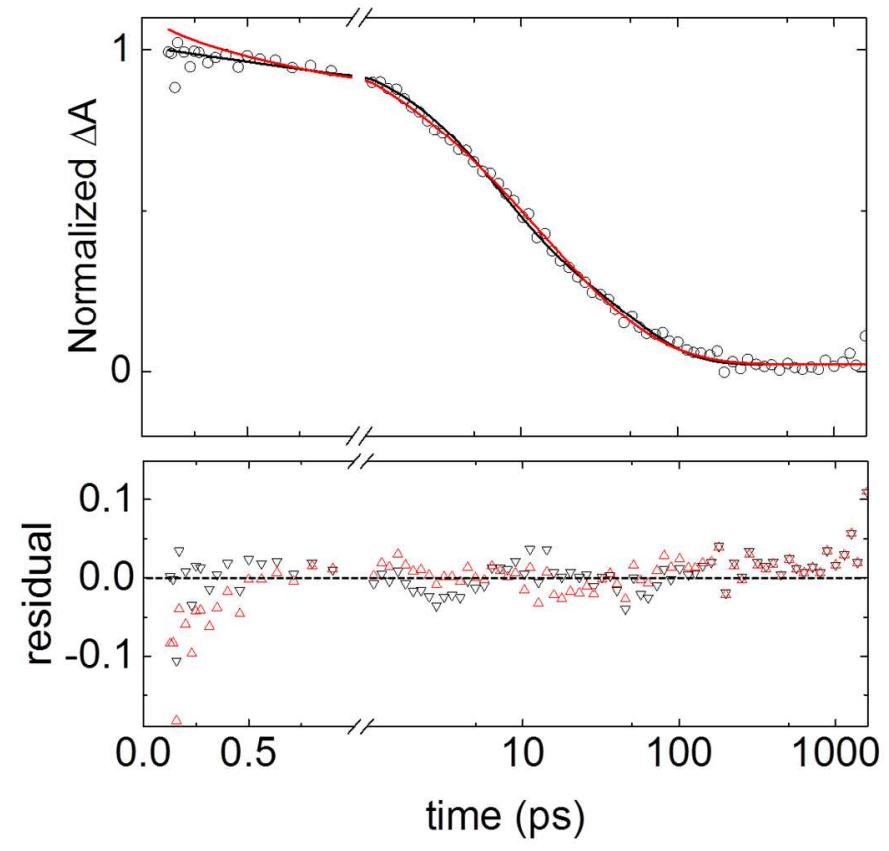

Figure S2. Plot of normalized signal as function of time (black circles) for $\mathbf{P}$ on $\mathrm{TiO}_{2}$. Biexponential (black line) and stretched exponential (Kohlrausch-Williams-Watts, red line) are plotted for comparison and residuals for each are shown in the lower plot. Parameters: biexponential function, $A_{f}=0.62, \tau_{f}=7.5 \mathrm{ps}, A_{s}=0.38, \tau_{s}=69 \mathrm{ps} ; \mathrm{KWW}, A_{K W W}=1.17, \tau_{K W W}=$ $13.6 \mathrm{ps}, \beta=0.53$. 


\section{Static Spectroscopy}

Ground state absorption spectra and photoluminescence:
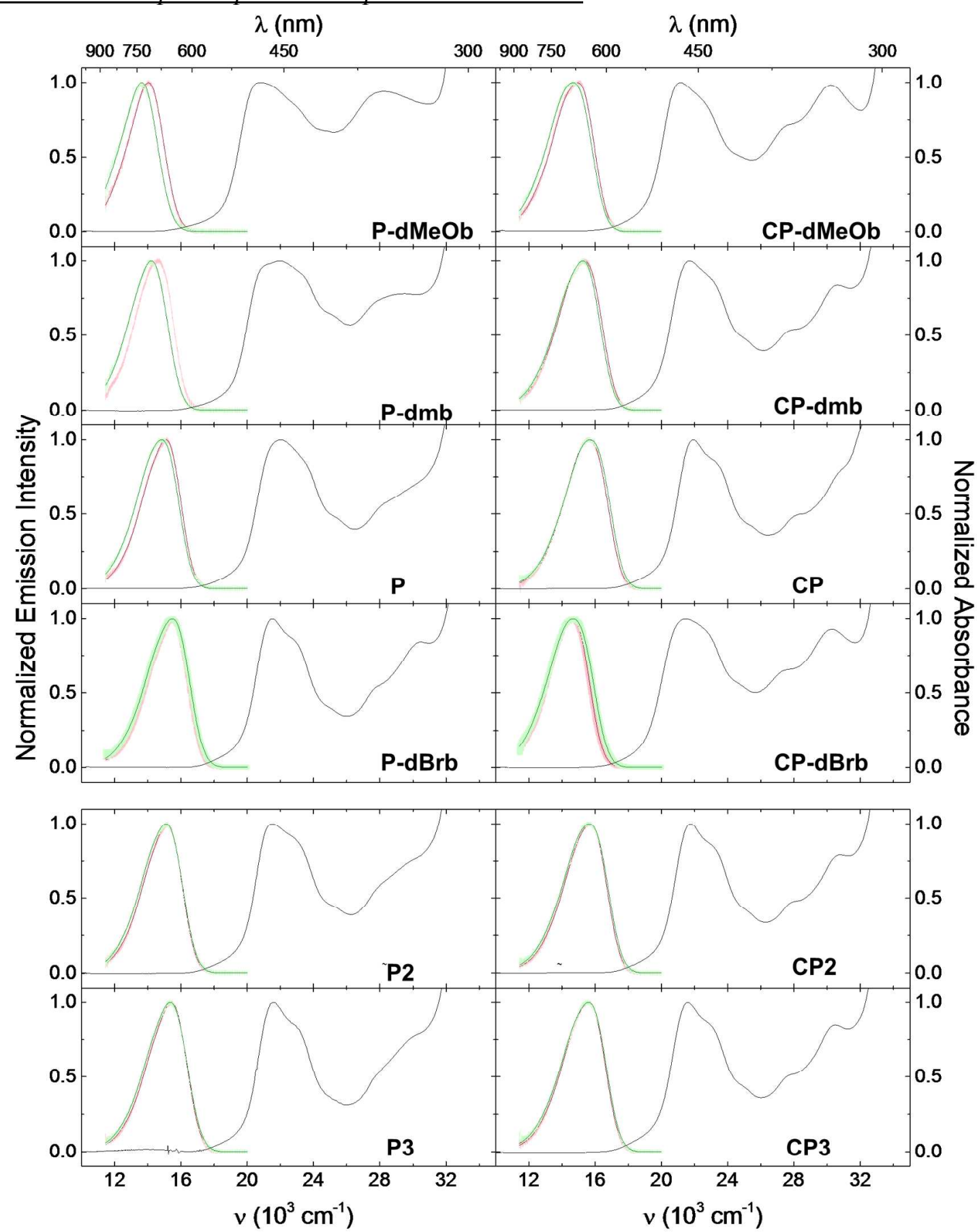

Figure S3. Solution absorption (black line) and photoluminescence (PL) (green) measured for each of the dyes studied here. Also shown is PL spectra from dyes adsorbed on $\mathrm{ZrO}_{2}$ (red). For all, conditions were deaerated $0.1 \mathrm{M} \mathrm{HClO}_{4}(a q)$.

Photoluminescence and Emission Spectral Fitting: Room temperature photoluminescence spectra were recorded for each chromophore in deaerated $0.1 \mathrm{M} \mathrm{HClO}_{4}(a q)$, either in solution or 
with the dye bound to a nanocrystalline $\mathrm{ZrO}_{2}$ film to mimic the interfacial environment of $\mathrm{TiO}_{2}$. The conduction band of $\mathrm{ZrO}_{2}$ is significantly higher in energy relative to $\mathrm{TiO}_{2}$, preventing injection from the surface-bound photoexcited dye and allowing for native relaxation to dominate. The solution photoluminescence of the $\mathbf{P x}$ and $\mathbf{C P x}$ series were discussed earlier, ${ }^{4}$ as were the spectra from P-dmb, P-dMeOb and P-dBrb on $\mathrm{ZrO}_{2}{ }^{1} \quad$ Ours match the previously reported values, with emission maxima between 630 and $730 \mathrm{~nm}$ for the series, Table S2.

Table S2. Room temperature photoluminescence data and results of emission spectral fitting for the series of chromophores in $0.1 \mathrm{M} \mathrm{HClO}_{4}(a q)$ free in solution or on $\mathrm{ZrO}_{2}{ }^{a}$

\begin{tabular}{|c|c|c|c|c|c|c|c|c|c|c|c|}
\hline \multirow[b]{2}{*}{ Dye } & \multicolumn{3}{|c|}{ Solution } & \multirow[b]{2}{*}{$\begin{array}{l}\hbar \omega \\
\left(\mathrm{cm}^{-1}\right)\end{array}$} & \multirow[b]{2}{*}{$S$} & \multicolumn{2}{|c|}{$\mathrm{ZrO}_{2}$} & \multirow[b]{2}{*}{$\begin{array}{l}\Delta \tilde{v}_{1 / 2} \\
\left(\mathrm{~cm}^{-1}\right)\end{array}$} & \multirow[b]{2}{*}{$\begin{array}{l}\hbar \omega \\
\left(\mathrm{cm}^{-1}\right)\end{array}$} & \multirow[b]{2}{*}{$S$} & \multirow[b]{2}{*}{$\begin{array}{l}\Delta \mathbf{E}_{\mathbf{0}}{ }^{-1} \\
\left(\mathrm{~cm}^{-1}\right)\end{array}$} \\
\hline & $\begin{array}{l}\lambda_{\max } \\
(\mathrm{nm})\end{array}$ & $\begin{array}{l}\mathbf{E}_{\mathbf{0}} \\
\left(\mathrm{cm}^{-1}\right)\end{array}$ & $\begin{array}{l}\Delta \tilde{v}_{1 / 2} \\
\left(\mathrm{~cm}^{-1}\right)\end{array}$ & & & $\begin{array}{l}\lambda_{\max } \\
(\mathrm{nm})\end{array}$ & $\begin{array}{l}\mathbf{E}_{\mathbf{0}} \\
\left(\mathrm{cm}^{-1}\right)\end{array}$ & & & & \\
\hline \multicolumn{12}{|l|}{ P-dRb } \\
\hline P-dMeOb & 723 & 13,800 & 1,930 & 1,410 & 0.62 & 704 & 14,200 & 1,900 & 1,400 & 0.59 & 400 \\
\hline P-dmb & 692 & 14,700 & 1,840 & 1,270 & 0.77 & 677 & 15,000 & 1,590 & 1,120 & 0.99 & 300 \\
\hline $\mathrm{P}$ & 663 & 15,300 & 1,720 & 1,210 & 1.02 & 656 & 15,400 & 1,690 & 1,250 & 0.84 & 100 \\
\hline P-dBrb & 636 & 15,800 & 1,860 & 1,350 & 0.90 & 637 & 15,800 & 1,770 & 1,330 & 0.84 & -50 \\
\hline \multicolumn{12}{|l|}{$\mathbf{P x}$} \\
\hline $\mathrm{P}$ & 663 & 15,300 & 1,720 & 1,210 & 1.02 & 656 & 15,400 & 1,690 & 1,250 & 0.84 & 100 \\
\hline $\mathrm{P} 2$ & 653 & 15,400 & 1,800 & 1,280 & 0.90 & 654 & 15,400 & 1,740 & 1,300 & 0.80 & 0 \\
\hline P3 & 641 & 15,700 & 1,890 & 1,350 & 0.83 & 643 & 15,700 & 1,790 & 1,340 & 0.78 & 0 \\
\hline \multicolumn{12}{|l|}{ CP-dRb } \\
\hline $\mathrm{CP}-\mathrm{dMeOb}$ & 663 & 15,200 & 1,750 & 1,230 & 1.12 & 660 & 15,300 & 1,670 & 1,230 & 1.04 & 150 \\
\hline CP-dmb & 647 & 15,600 & 1,830 & 1,340 & 0.93 & 640 & 15,800 & 1,750 & 1,260 & 1.08 & 200 \\
\hline $\mathrm{CP}$ & 627 & 16,300 & 1,750 & 1,230 & 1.16 & 628 & 16,200 & 1,730 & 1,170 & 1.11 & -100 \\
\hline CP-dBrb & 661 & 15,300 & 1,790 & 1,210 & 1.21 & 672 & 15,000 & 1,740 & 1,200 & 1.00 & -300 \\
\hline \multicolumn{12}{|l|}{ CPx } \\
\hline $\mathrm{CP}$ & 627 & 16,300 & 1,750 & 1,230 & 1.16 & 628 & 16,200 & 1,730 & 1,170 & 1.11 & -100 \\
\hline $\mathrm{CP} 2$ & 628 & 16,200 & 1,790 & 1,280 & 1.07 & 628 & 16,100 & 1,760 & 1,280 & 0.94 & -100 \\
\hline $\mathrm{CP} 3$ & 632 & 16,000 & 1,810 & 1,330 & 0.98 & 632 & 16,000 & 1,760 & 1,270 & 0.96 & 0 \\
\hline
\end{tabular}

${ }^{a}$ The errors associated with each of the values are $\pm 2 \mathrm{~nm}$ for the measure PL maxima and $\pm 1-2 \%$ for values resulting from spectral fitting, ${ }^{b}$ Difference between $\mathbf{E}_{\mathbf{0}}$ measured on $\mathrm{ZrO}_{2}$ and in free solution. Negative values indicate a redshift upon binding to $\mathrm{ZrO}_{2}$.

The photoluminescence spectra were treated by simplified Frank-Condon analysis using a singlemode approximation, ${ }^{4,13}$ after spectral correction, to find $\mathrm{I}(\tilde{v})$, the wavenumber dependent intensity, i.e.:

$$
I(\tilde{v})=\sum_{v=0}^{11}\left(\frac{\mathbf{E}_{\mathbf{0}}-v \hbar \omega}{\mathbf{E}_{\mathbf{0}}}\right)^{3}\left(\frac{S^{v}}{v !}\right) \exp \left(-\ln 16 \cdot\left(\frac{\tilde{v}-\mathbf{E}_{\mathbf{0}}+v \hbar \omega}{\Delta \tilde{v} 1 / 2}\right)^{2}\right)
$$

where the mode quantum number is $v$, and the difference between lowest vibrational levels of GS and MLCT state $\left(\mathbf{E}_{\mathbf{0}}\right)$, the mode spacing $(\hbar \omega)$, mode full-width half maximum $(\Delta \tilde{v} 1 / 2)$, and Huang-Rhys factor $(S)$ were used as fitting parameters in the non-linear least squares fit to the 
experimental data (Trust-Region). The results of spectral fitting are presented along with the experimental spectra in Figure S4.
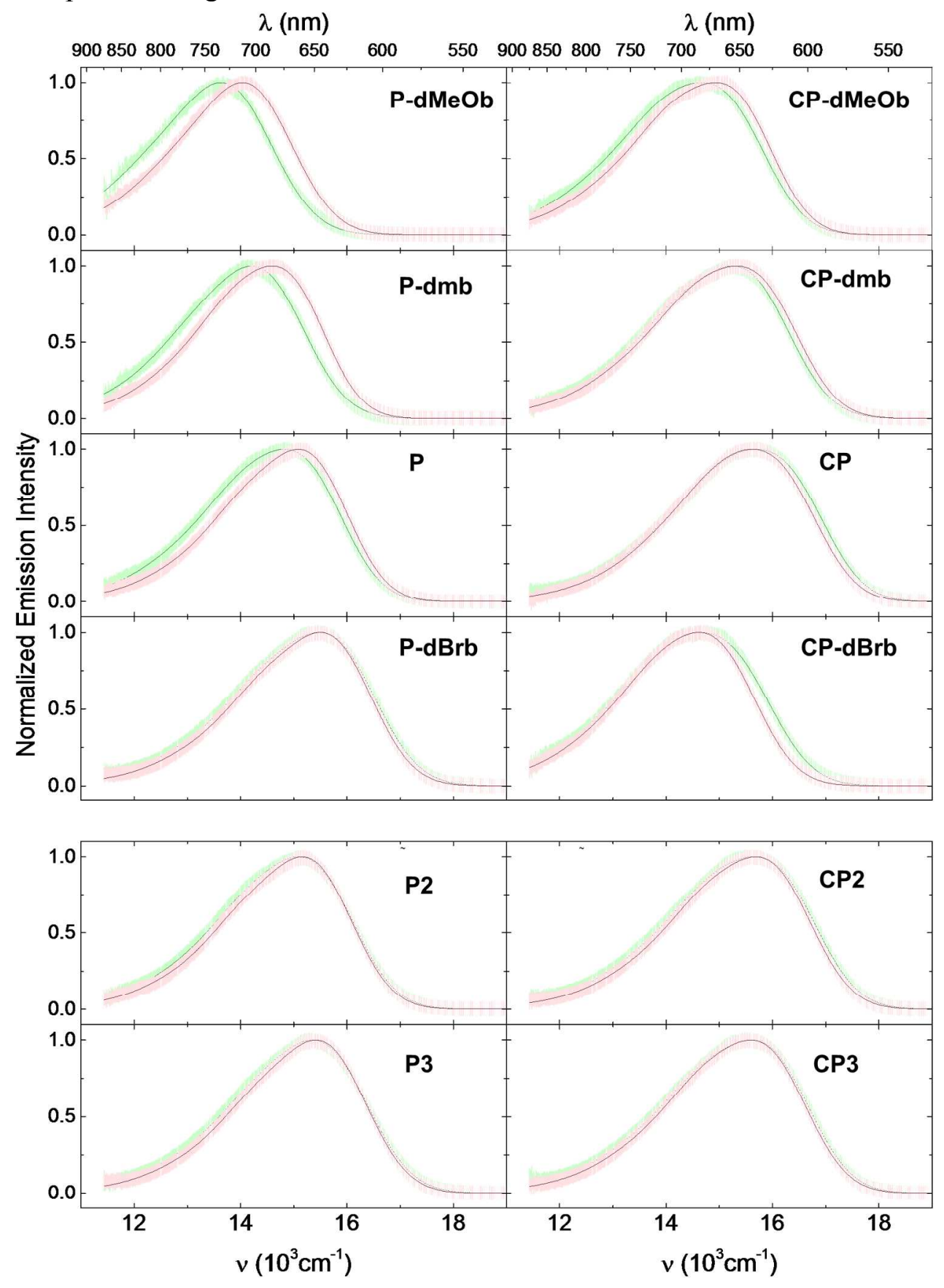

Figure S4. Room temperature, steady-state photoluminescence spectra for each of the dyes used in this study acquired in argon deoxygenated $0.1 \mathrm{M} \mathrm{HClO}_{4}(a q)$ either free in solution (green) or attached to nanocrystalline $\mathrm{ZrO}_{2}(s)$ (red). Dark lines are spectra predicted from spectral fitting.

The emission spectra are dominated by a broad band centered near $650 \mathrm{~nm}$, characteristic of photoluminescence from the triplet metal-to-ligand charge transfer excited state, ${ }^{3} \mathrm{MLCT}$. A 
detailed discussion of the emission spectra along with a comparison of solution and $\mathrm{ZrO}_{2}$ bound dyes can be found in the main text.

\section{Solution Electrochemistry:}

The solution electrochemistry of each dye in the P-dRb series was compared to the homoleptic analog, $\mathrm{Ru}(\mathrm{dRb})_{3}{ }^{2+}$. Inclusion of the phosphonated bpy ligand (bpyP) shifts the $E^{\circ}\left(\mathrm{Ru}^{\mathrm{III} / \mathrm{II}}\right)$ to more positive potentials for the complexes containing 4,4'-dimethoxy-bpy (dMeOb), 4,4'-dimethyl-bpy (dmb) and bpy ancillary ligands. In the case of 4,4'-bromo-bpy (dBrb) the homoleptic complex is less easily oxidized. Although these comparisons might suggest that the bpyP ligand is more electron deficient than all but $\mathrm{dBrb}$, comparing the first reductive wave is more confusing. In each case, replacing one ligand from the homoleptic complexes with bpyP causes an equipotential shift in both the first oxidative wave and the first reductive wave relative to the open circuit condition.

Table S3. Comparing the reduction potentials $E^{\circ}\left(\mathrm{Ru}^{\mathrm{III} / \mathrm{II}}\right)$ and $E^{\circ}\left(\mathrm{Ru}^{\mathrm{II} / \mathrm{II}}\right)$ for the $\mathbf{P}-\mathbf{d R b}$ series to their homoleptic counterparts, all versus NHE. ${ }^{a}$

\begin{tabular}{|c|c|c|c|}
\hline Dye & $E^{\circ}\left(\mathrm{Ru}^{\mathrm{III} / \mathrm{II}}\right)(\mathrm{V})$ & $E_{1 / 2}^{\mathrm{II} / \mathrm{I}}(\mathrm{V})$ & $\Delta E_{1 / 2}(\mathrm{~V})$ \\
\hline $\mathbf{P}$ & 1.27 & -1.29 & 2.56 \\
\hline$\left[\mathrm{Ru}(\mathrm{bpy})_{3}\right]^{2+}$ & 1.30 & -1.27 & 2.57 \\
\hline $\mathbf{P 2}$ & 1.23 & -1.39 & 2.62 \\
\hline P-dMeOb & 1.05 & -1.33 & 2.38 \\
\hline$\left[\mathrm{Ru}(\mathrm{dMeOb})_{3}\right]^{2+}$ & 0.95 & -1.41 & 2.36 \\
\hline P-dmb & 1.16 & -1.37 & 2.49 \\
\hline$\left[\mathrm{Ru}(\mathrm{dmb})_{3}\right]^{2+}$ & 1.13 & -1.38 & 2.51 \\
\hline P-dBrb & 1.40 & $-1.19^{b}$ & $2.49^{b}$ \\
\hline$\left[\mathrm{Ru}(\mathrm{dBrb})_{3}\right]^{2+}$ & 1.53 & $-0.98^{b}$ & $2.51^{b}$ \\
\hline \multicolumn{4}{|c|}{$\begin{array}{l}{ }^{a} \text { The potential in } 4: 1 \mathrm{v} / \mathrm{v} \mathrm{MeCN} / \mathrm{H}_{2} \mathrm{O} \text { with } 0.1 \mathrm{M}^{n} \mathrm{Bu}_{4} \mathrm{NPF}_{6} \\
\text { was measured using a glassy carbon working electrode and } \\
\text { platinum wire auxiliary against } \mathrm{Ag} / \mathrm{AgNO}_{3} \text { calibrated against } \\
\mathrm{SCE}(0.241 \mathrm{~V} \text { vs NHE) and the } \mathrm{Ru}(\mathrm{III} / \mathrm{II}) \text { couple of } \\
{\left[\mathrm{Ru}(\mathrm{bpy})_{3}\right]^{2+}\left(1.26 \mathrm{~V} \text { vs NHE). }{ }^{b} \text { Irreversible reduction, } E_{p c} \text {, }\right.} \\
\Delta E \text { is the difference between } E_{\mathrm{pc}}(\mathrm{III} \rightarrow \mathrm{II}) \text { and } E_{\mathrm{pc}}(\mathrm{II} \rightarrow \mathrm{I}) .\end{array}$} \\
\hline
\end{tabular}

In an attempt to address the question of relative alignment of ligand energies, we compared the first reduction potentials of each dye in the P-dRb series with the homoleptic counterpart (Table S3). The first reduction is to a ligand centered orbital, and by comparing these we hoped to identify in which systems the surface bound ligand was lowest. Within this series, however, any shift in potential at the first reduction is matched at the $\mathrm{Ru}(\mathrm{III} / \mathrm{II})$ couple, indicating that the destabilizing effects of the electron donating substituents that are imparted on the $\mathrm{Ru}(\mathrm{d} \pi)$ orbital are also imparted to the $\pi^{*}$ orbitals of all three ligands. Because the energies of all the orbitals are affected by the substituents, it is not possible to determine the relative energies of the ligands by comparing electrochemical observations made on two different compounds. The one 
exception, perhaps, is the case of P-dBrb where the first reduction is irreversible at $100 \mathrm{mV} / \mathrm{s}$ scan rate, as is the first reduction of $\mathrm{Ru}(\mathrm{dBrb})_{3}{ }^{2+}$. This irreversibility is most likely due a to chemical step that follows the reduction of the $\mathrm{dBrb}$ ligand in both the dye and the model complex, ${ }^{14}$ which suggests that in the P-dBrb complex, the dBrb ligand is lowest in energy.

\section{E. Frontier orbitals from DFT calculations:}

The results of DFT calculations performed on dyes in the P-dRb and CP-dRb series were compared, and are discussed in the main text. Orbitals resulting from those calculations (HOMO, LUMO, LUMO+1, LUMO+2) are presented in Figures S5 and S6.
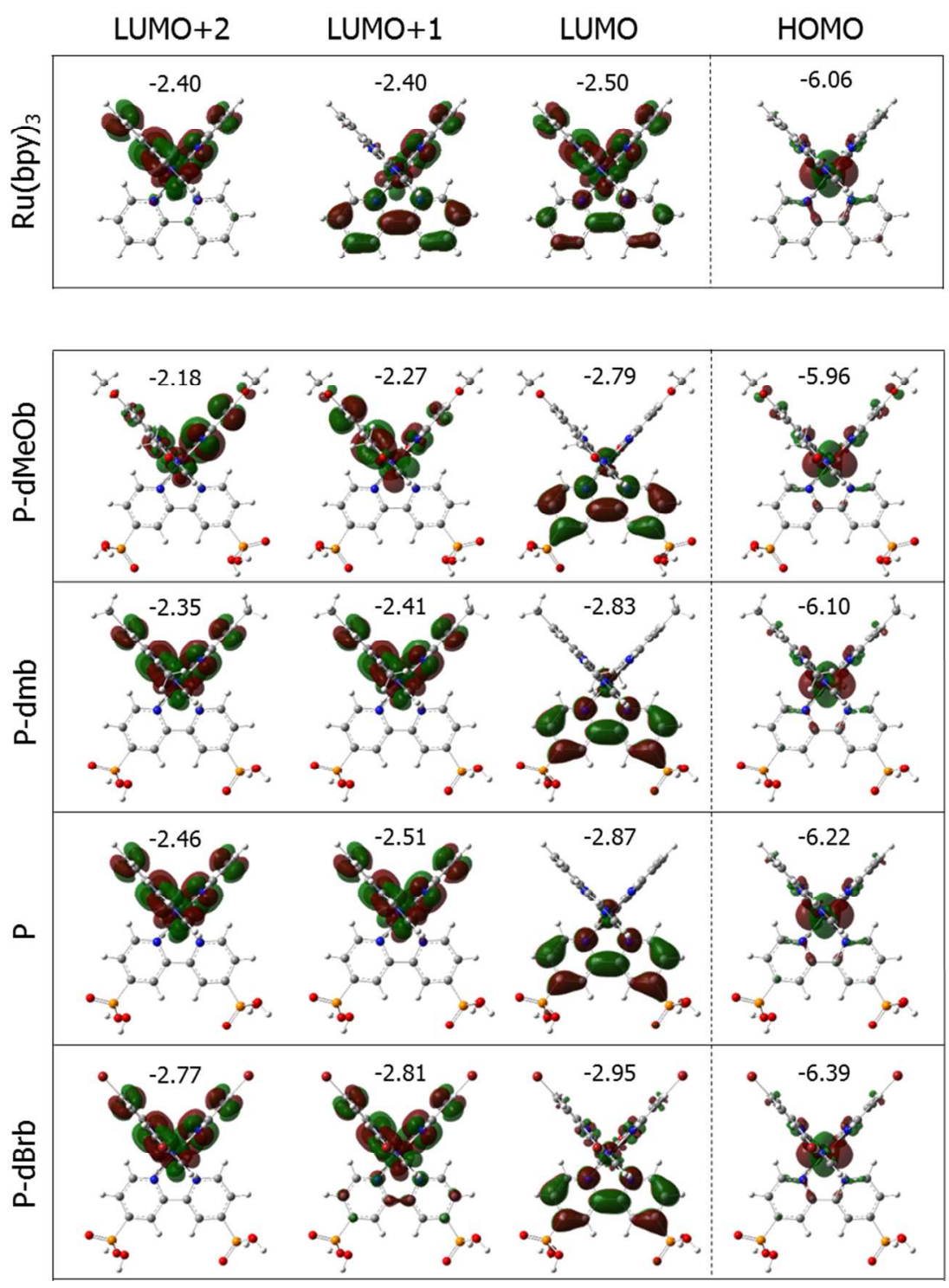

Figure S5. Frontier orbitals calculated for $\mathrm{Ru}(\mathrm{bpy})_{3}{ }^{2+}$ and the P-dRb series of Ru(II) dyes using the B3LYP functional. Calculations were performed using the LANL2DZ basis set for Ru and $6-31 \mathrm{G}^{* *}$ basis set for the other atoms. 


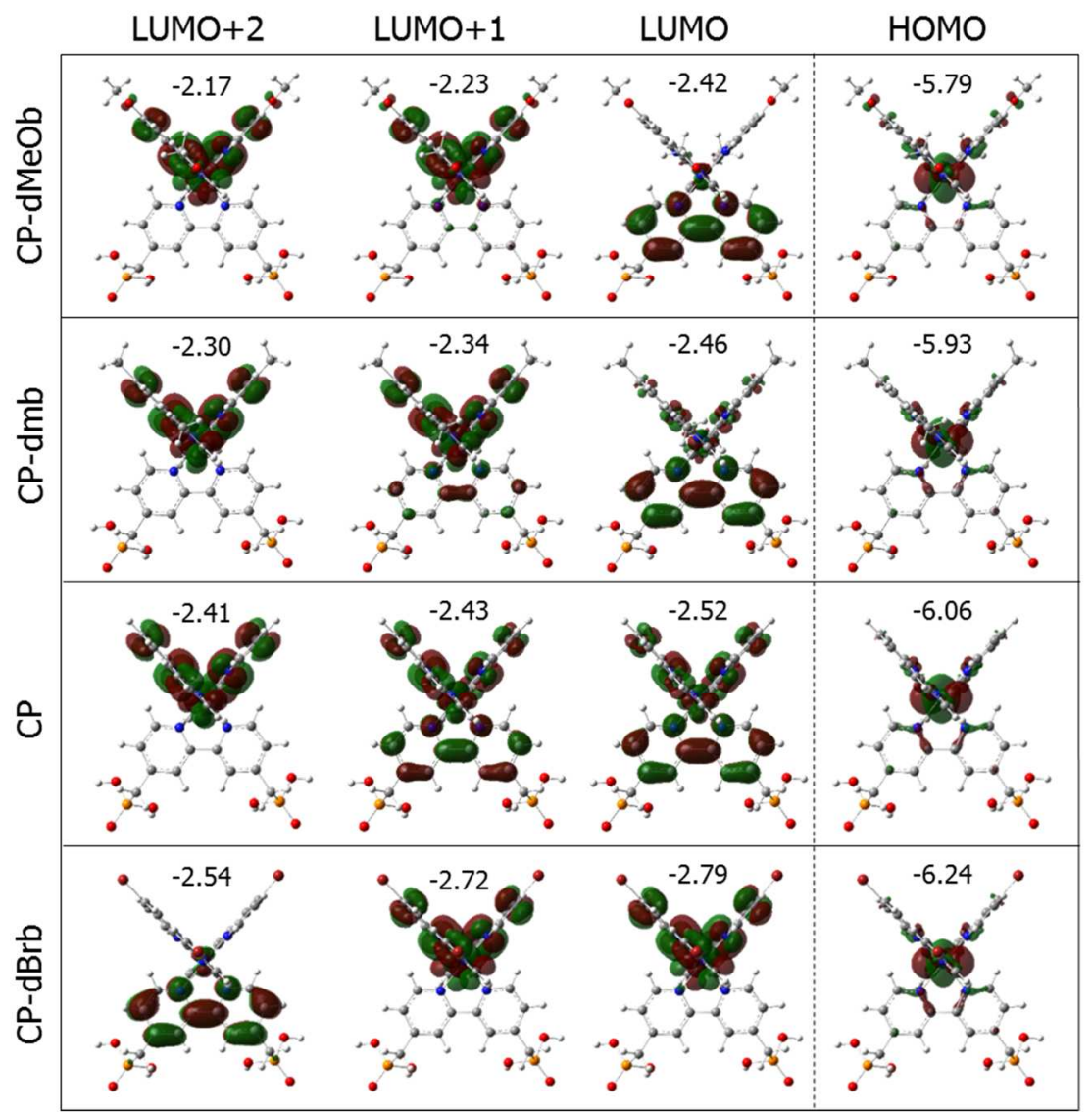

Figure S6. Frontier orbitals calculated for the CP-dRb series of $\mathrm{Ru}(\mathrm{II})$ dyes, calculated using the B3LYP functional. Calculations were performed using the LANL2DZ basis set for Ru and $6-31 \mathrm{G}^{* *}$ basis set for the other atoms.

\section{F. Spectroelectrochemistry Determination of $\mathrm{TiO}_{2}$ Density of States Function}

Spectroelectrochemistry was used to characterize the conduction band edge of the dyed nanocrystalline $\mathrm{TiO}_{2}$ films used in the TA experiments in $0.1 \mathrm{M} \mathrm{HClO}_{4}(a q)$ (Figure S7) using methods developed by Fitzmaurice and others. ${ }^{15,16}$ Briefly, absorption spectra were measured while applying a potential bias to the film $\left(E_{a}\right)$. The number of conduction band levels at each applied potential was calculated from the measured absorption at $800 \mathrm{~nm}$ using the previously reported extinction value for conduction band electrons $\left(\varepsilon^{800 \mathrm{~nm}}=10^{3} \mathrm{M}^{-1} \mathrm{~cm}^{-1}\right)$. The typically observed porosity for these films $(0.40 \pm 0.02 \mathrm{v} / \mathrm{v}$ film), and the measured film thickness $(4.6 \pm$ $0.3 \mu \mathrm{m})$ were also used in this calculation. Electronic absorption spectra of the film taken before and after the spectroelectrochemical experiment were minimally changed and no free dye was detectable in the electrolyte solution afterward, suggesting that little dye desorbed over the course of a single experiment (ca. 30 min for the full cycle stepping to about $-800 \mathrm{mV}$ and back). Recent publications have implicated intercalation of cations $\left(\mathrm{H}^{+}, \mathrm{Li}^{+}\right.$, etc) as forming irreversible trap states under open circuit conditions ${ }^{17}$ and also that these traps can be depopulated at sufficiently positive potentials. ${ }^{18}$ We did not observe spectroscopic evidence of "irreversible" trapped states at about $\sim 425 \mathrm{~nm}$ until potentials negative of $-0.6 \mathrm{~V}$ vs. NHE were applied (Figure S8). This suggests that large, negative potentials induce an irreversible chemical 
change at the interface that does not reflect the distribution of levels or states on the unperturbed surface.

While the nature of the irreversible change is unclear, its existence is likely not relevant to the femtosecond spectroscopy discussed in this article. Since our TA experiments are performed with low fluence and with sample translation, the surface charges achieved here most likely never approach those obtained under negative bias. Transient absorption using the same conditions and excitation source, but observing over $400 \mu$ s confirm the return to the original state between pump pulses.
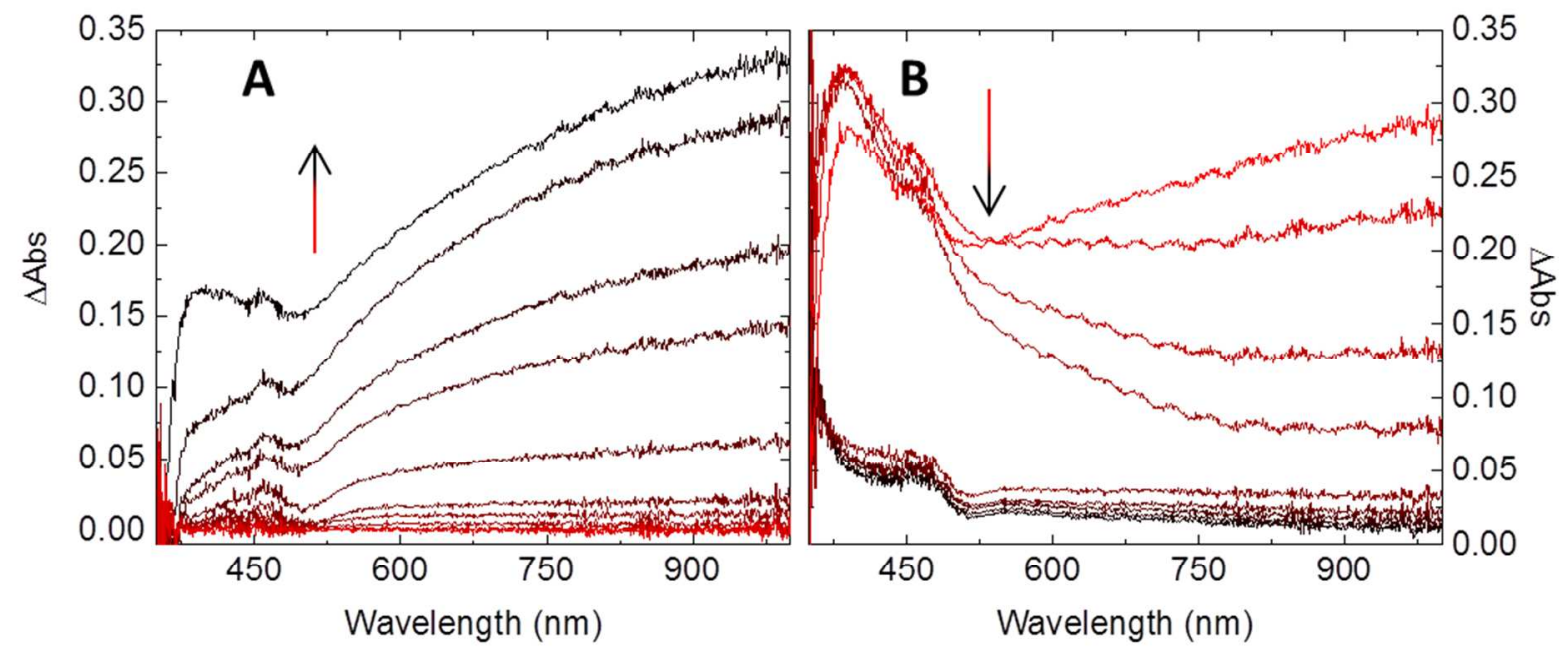

Figure S7. Difference spectra obtained by applying A) progressively negative bias to a $\mathrm{TiO}_{2}$ film in $0.1 \mathrm{M} \mathrm{HClO}_{4}(0.1 \rightarrow-0.8 \mathrm{~V}$ vs NHE$)$ and $\left.\mathrm{B}\right)$ then stepping in the positive direction.

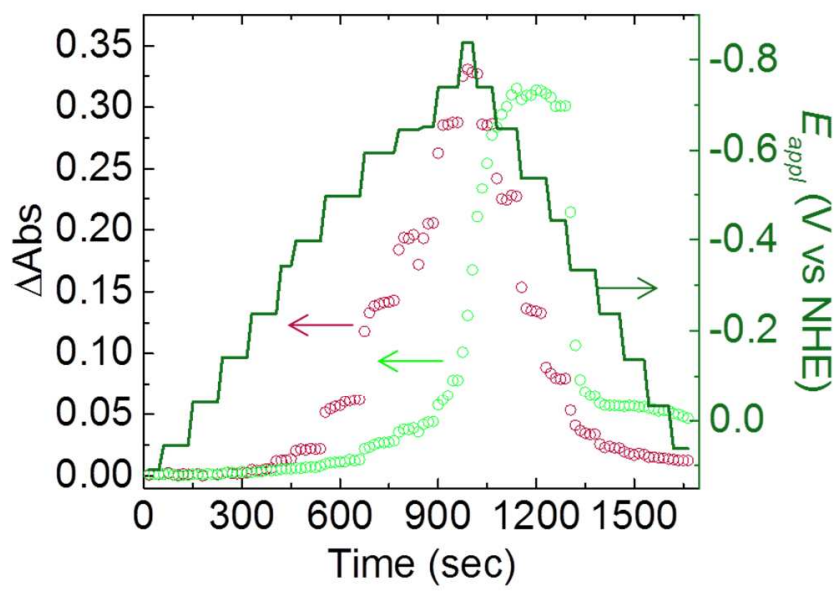

Figure S8. Plot showing the spectral change at $900 \mathrm{~nm}$ (red points) and $400 \mathrm{~nm}$ (green points) of dyed $\mathrm{TiO}_{2}$ under applied bias for a single spectroelectrochemical measurement. The solid green shows the potential steps on the same time coordinate (green line). 
The distribution of levels observed by spectroelectrochemistry were fit to the density of states function put forth by Bisquert and coworkers, (eq 9, main text) and also to a charge layer accumulation model proposed by Rothenberger et al., ${ }^{8}$ i.e.;

$$
\rho\left(E_{a}\right)=\int_{E_{0}}^{E_{a}} \frac{\alpha}{k_{B} T} \frac{g(\sqrt{E}) N_{X}}{\exp \left(\frac{\alpha}{k_{B} T}\left(E_{C B}-E\right)\right)+1} d E
$$

Parameters used to fit the observed data are presented in Table S4.

Table S4. Fitting parameters result from fitting DOS

\begin{tabular}{cccc}
\hline Model & $N_{X}\left(\times 10^{20}\right) \mathrm{cm}^{-3}$ & $E_{C B}(\mathrm{~V}$ vs NHE $)$ & $\alpha$ \\
\hline Bisquert & $0.086( \pm 0.025)$ & -0.22 & $0.29( \pm 0.01)$ \\
Fitzmaurice & $45( \pm 5)$ & -0.53 & $0.32( \pm 0.01)$ \\
\hline
\end{tabular}

\section{G. Picosecond Evolution on the Surface}

Evidence for the 50 to 100 ps time constant implied by the analysis of our kinetic data is obtained by comparing the spectral evolution of the $\mathbf{P}$ dye on $\mathrm{ZrO}_{2}$ and in solution, Figure S9. The spectral changes observed both in solution and on the surface are small. This is not that surprising since the excited state absorption features in Ru polypyridyl complexes are not terribly sensitive to the vibrational state, or the identity of the low-lying ${ }^{3}$ MLCT state. While the spectral changes are subtle, there are noticeable differences between the two environments. In solution there is a slight increase in the $387 \mathrm{~nm}$ absorption at early times (first $5 \mathrm{ps}$ ), but on longer time scales the spectra are essentially static. When the complex is adsorbed onto $\mathrm{ZrO}_{2}$, we no longer observed any changes in the $387 \mathrm{~nm}$ absorption. We do, however, observe a slight blue shift in the low energy side of the bleach, resulting in a narrowing of the band on longer time scales. This narrowing takes place without significant changes in the magnitude of the bleach, indicating that the observed spectral changes reflect relaxation on the excited state, and not excited state decay, suggesting that this spectral evolution is probably the result of a time-dependent blue shift of the weak excited state absorption band in the visible. An expanded view of this systematic shift in the $\mathrm{ZrO}_{2}$ spectra is shown in the inset. We note that no systematic shift in the bleach feature is observed for $\mathbf{P}$ in solution, underscoring the differences between the two environments. The $\mathrm{ZrO}_{2}$ transient at $487 \mathrm{~nm}$ indicates that this spectral change occurs with both fast (2 ps) and slow (100 ps) time constants, the slower of which is comparable to the 70 ps time extracted from the kinetic model. Although it is difficult to definitively assign this evolution to a specific physical process, vibrational cooling and/or relaxation amongst the low-lying ${ }^{3}$ MLCT states are certainly plausible. In short, the comparison of the two sets of spectra does show that there is an excited state relaxation process taking place on $100 \mathrm{ps}$ time scale for the $\mathrm{Ru}$ complexes bound to $\mathrm{ZrO}_{2}$ (and probably $\mathrm{TiO}_{2}$, as well) that is not present in solution. 


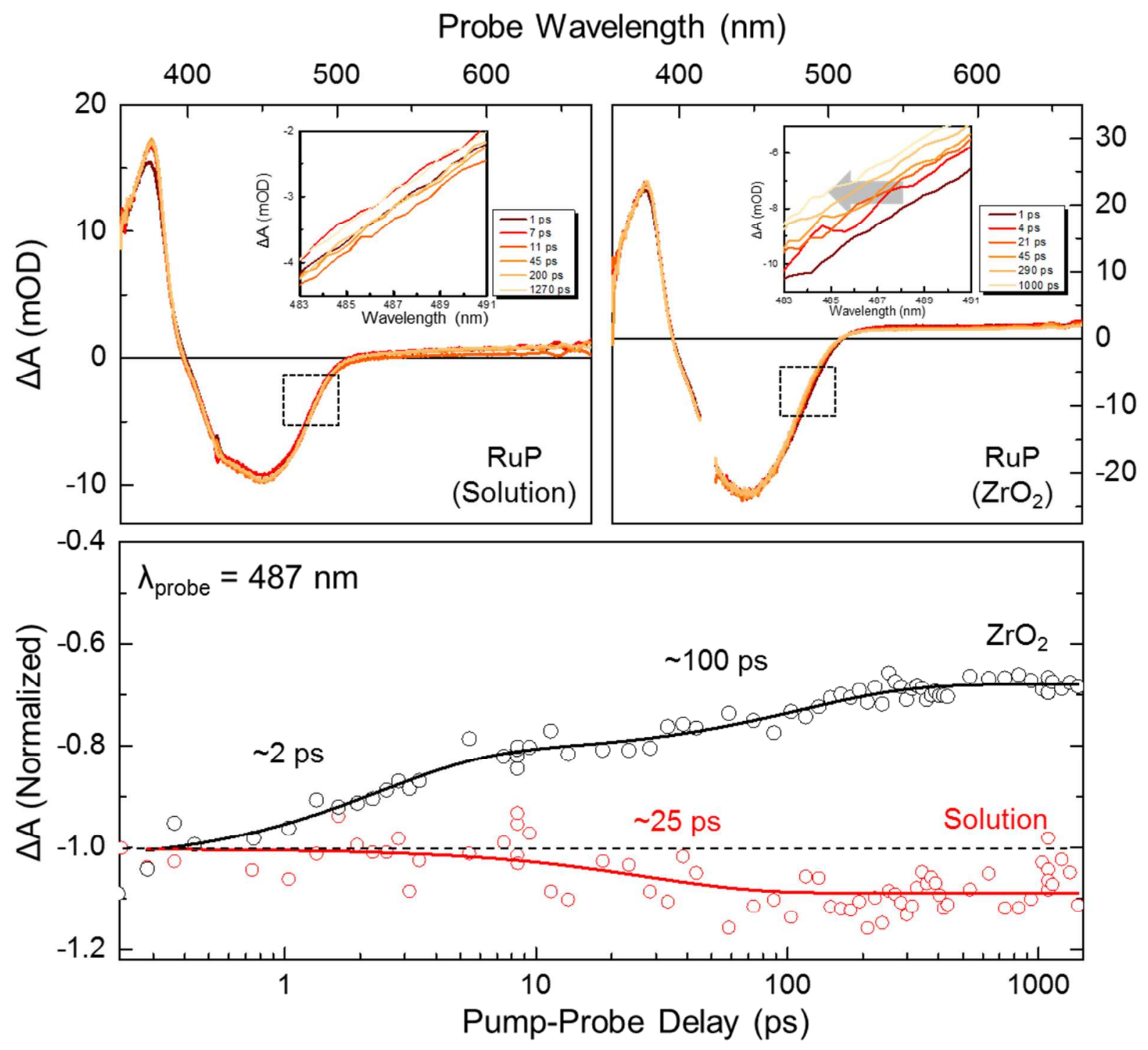

Figure S9: Transient absorption spectra for the dye $\mathbf{P}$ on $\mathrm{ZrO}_{2}$ (Top Right) and in solution (Top Left). Solvent is argon deaerated $0.1 \mathrm{M} \mathrm{HClO}_{4}(a q)$, and excitation is $420 \mathrm{~nm}(100 \mathrm{~nJ} / \mathrm{pulse})$. Inset shows an expanded view in the region indicate by the dashed boxes. (Bottom) Normalized transients at a probe wavelength of $487 \mathrm{~nm}$.

H. Kinetic Model and Derivation of Integrated Rate Law: To arrive at an analytical solution for the decay of the normalized signal at $375 \mathrm{~nm}$ (See Scheme 1 and eq 11 in the main text):

$$
\Delta \tilde{\mathrm{A}}_{t}^{R}=\frac{1}{P_{i}^{\mathrm{T}}}\left(P_{t}^{\mathrm{n}}+P_{t}^{0}\right)
$$

first a solution is found for the time dependent population of fast injecting MLCT, $P_{t}^{n}$ :

$$
-\frac{d P_{t}^{n}}{d t}=k_{i n j}^{n} P_{t}^{n}+k_{n 0} P_{t}^{n}
$$




$$
\int_{P_{i}^{n}}^{P_{t}^{n}} \frac{d P_{t}^{n}}{P_{t}^{n}}=-\left(k_{i n j}^{n}+k_{n 0}\right) \int_{0}^{t} d t
$$

which upon integration gives:

$$
P_{t}^{n}=P_{i}^{n} e^{-\left(k_{i n j}^{n}+k_{n 0}\right) t}
$$

This expression for the time dependent population is further expanded to account for portions either injecting into to $\mathrm{TiO}_{2}$ or relaxing to the slower injecting population:

$$
P_{t}^{n}=\underbrace{\frac{k_{i n j}^{n}}{k_{i n j}^{n}+k_{n 0}} P_{i}^{n} e^{-\left(k_{i n j}^{n}+k_{n 0}\right) t}}_{\text {Portion injecting into } \mathrm{TiO}_{2}}+\underbrace{\frac{k_{n 0}}{k_{i n j}^{n}+k_{n 0}} P_{i}^{n} e^{-\left(k_{i n j}^{n}+k_{n 0}\right) t}}_{\text {Portion relaxing to }|0\rangle}
$$

For the slower injecting population of ${ }^{3}$ MLCT states, $P_{t}^{0}$, rate terms are included for both population loss by injection and formation by cooling:

$$
-\frac{d P_{t}^{0}}{d t}=k_{i n j}^{0} P_{t}^{0}-k_{n 0} P_{t}^{n}
$$

Using eq S6 to substitute for $P_{t}^{n}$ gives the expression

$$
-\frac{d P_{t}^{0}}{d t}=k_{i n j}^{0} P_{t}^{0}-k_{n 0} P_{i}^{n} e^{-\left(k_{i n j}^{n}+k_{n 0}\right) t}
$$

The approach to solving this problem uses a standard method. ${ }^{19}$ The first step is to rearrange eq S9 to

$$
0=d P_{t}^{0}+k_{i n j}^{0} P_{t}^{0} d t-k_{v c} P_{i}^{n} e^{-\left(k_{i n j}^{n}+k_{v c}\right) t} d t
$$

Next define an equivalent potential function $F\left(t, P_{t}^{0}\right)$ such that

$$
0=d F\left(t, P_{t}^{0}\right)=(I \cdot f) d P_{t}^{0}+(J \cdot f) d t
$$

and where, $f$ is the integration factor needed to make the eq $\mathrm{S} 11$ exact, i.e.

$$
I \cdot f=\left(\frac{\partial F\left(t, P_{t}^{0}\right)}{\partial P_{t}^{0}}\right)_{t} \quad \text { and } \quad J \cdot f=\left(\frac{\partial F\left(t, P_{t}^{0}\right)}{\partial t}\right)_{P_{t}^{0}}
$$

and

$$
\left(\frac{\partial I \cdot f}{\partial t}\right)_{P_{t}^{0}}=\left(\frac{\partial J \cdot f}{\partial P_{t}^{0}}\right)_{t}
$$

To solve for the potential function, integrate with respect to $t$ keeping $P_{t}^{0}$ fixed,

$$
F\left(t, P_{t}^{0}\right)=\int(J \cdot f) d t+K\left(P_{t}^{0}\right)
$$


Where $K\left(P_{t}^{0}\right)$ is a function that accounts for holding $P_{t}^{0}$ constant. Taking the partial derivative with respect to $P_{t}^{0}$ at constant $t$ gives

$$
\left(\frac{\partial F\left(t, P_{t}^{0}\right)}{\partial P_{t}^{0}}\right)_{t}=\left(\frac{\partial}{\partial P_{t}^{0}} \int(J \cdot f) d t+K\left(P_{t}^{0}\right)\right)_{t}
$$

which from $\mathrm{S} 12$ is expressed as:

$$
I \cdot f=\left(\frac{\partial}{\partial P_{t}^{0}} \int(J \cdot f) d t\right)_{t}+\frac{d K\left(P_{t}^{0}\right)}{d P_{t}^{0}}
$$

and after solving for $K\left(P_{t}^{0}\right)$

$$
K\left(P_{t}^{0}\right)=\int I \cdot f-\left(\frac{\partial}{\partial P_{t}^{0}} \int(J \cdot f) d t\right)_{t} d P_{t}^{0}
$$

can be substituted back into eq S14. After applying the limits of integration

$$
F\left(t, P_{t}^{0}\right)=\int_{0}^{t}(J \cdot f) d t+\int_{P_{i}^{0}}^{P_{t}^{0}}\left[I \cdot f-\frac{\partial}{\partial P_{t}^{0}} \int_{0}^{t}(J \cdot f) d t\right] d P_{t}^{0}
$$

and using the following definitions

$$
\begin{aligned}
& f=e^{k_{i n j}^{0} t} \\
& I=1 \\
& J=k_{i n j}^{0} P_{t}^{0}-k_{n 0} P_{i}^{n} e^{-\left(k_{i n j}^{n}+k_{n 0}\right) t}
\end{aligned}
$$

the expression for the potential function is arrived at, i.e.

$$
\begin{aligned}
0=k_{i n j}^{0} P_{t}^{0} \int_{0}^{t} e^{k_{i n j}^{0} t} d t-k_{n 0} P_{i}^{n} \int_{0}^{t} e^{k_{i n j}^{0}-\left(k_{i n j}^{0}+k_{n 0}\right) t} d t \\
+\int_{P_{i}^{0}}^{P_{t}^{0}}\left[e^{k_{i n j}^{0} t}-\frac{\partial}{\partial P_{t}^{0}} \int_{0}^{t}\left(k_{i n j}^{0} P_{t}^{0} \int_{0}^{t} e^{k_{i n j}^{0} t} d t-k_{n 0} P_{i}^{n} \int_{0}^{t} e^{k_{i n j}^{0}-\left(k_{i n j}^{0}+k_{n 0}\right) t} d t\right)\right] d P_{t}^{0}
\end{aligned}
$$

Evaluating the integrals gives

$$
0=k_{i n j}^{0} P_{t}^{0}\left(e^{k_{i n j}^{0} t}-1\right)-\frac{k_{n 0} P_{i}^{n}\left(e^{k_{i n j}^{0}-\left(k_{i n j}^{n}+k_{n 0}\right) t}-1\right)}{k_{i n j}^{0}-\left(k_{i n j}^{n}+k_{n 0}\right)}+P_{t}^{0}-P_{i}^{0}
$$

and simplifying gives the analytical integrated rate law for the population in $|0\rangle$, i.e.

$$
P_{t}^{0}=\left(P_{i}^{0}+\frac{k_{n 0} P_{i}^{n}}{k_{i n j}^{n}+k_{n 0}-k_{i n j}^{0}}\right) e^{-k_{i n j}^{0} t}-\frac{k_{n 0}}{k_{i n j}^{n}+k_{n 0}-k_{i n j}^{0}} P_{i}^{n} e^{-\left(k_{i n j}^{n}+k_{n 0}\right) t}
$$

Making the assumption that $k_{i n j}{ }^{0}$ is small relative to $k_{i n j}{ }^{n}+k_{n 0}$, and substituting eqs S7 and S24 into the numerator of eq $\mathrm{S} 3$, 


$$
\begin{aligned}
\left(P_{t}^{n}+P_{t}^{0}\right)=\frac{k_{i n j}^{n}}{k_{i n j}^{n}+} k_{n 0} & P_{i}^{n} e^{-\left(k_{i n j}^{n}+k_{n 0}\right) t}+\frac{k_{n 0}}{k_{i n j}^{n}+k_{n 0}} P_{i}^{n} e^{-\left(k_{i n j}^{n}+k_{n 0}\right) t} \\
& +\left(P_{i}^{0}+\frac{k_{n 0} P_{i}^{n}}{k_{i n j}^{n}+k_{n 0}}\right) e^{-k_{i n j}^{0} t}-\frac{k_{n 0}}{k_{i n j}^{n}+k_{n 0}} P_{i}^{n} e^{-\left(k_{i n j}^{n}+k_{n 0}\right) t}
\end{aligned}
$$

which upon dividing through by $P_{i}^{T}\left(=P_{i}^{0}+P_{i}^{n}\right)$ and simplifying leaves

$$
\Delta \tilde{\mathrm{A}}_{t}^{R}=\frac{k_{i n j}^{n}}{k_{i n j}^{n}+k_{n 0}} \cdot \frac{P_{i}^{n}}{P_{i}^{T}} e^{-\left(k_{i n j}^{n}+k_{n 0}\right) t}+\left(\frac{P_{i}^{0}}{P_{i}^{T}}+\frac{k_{n 0}}{k_{i n j}^{n}+k_{n 0}} \cdot \frac{P_{i}^{n}}{P_{i}^{T}}\right) e^{-k_{i n j}^{0} t}
$$

which is the same as eq 13 in the main text when normalized to the initial population, $P_{i}^{\mathrm{T}}=1$.

\section{References}

(1) Ashford, D. L.; Brennaman, M. K.; Brown, R. J.; Keinan, S.; Concepcion, J. J.; Papanikolas, J. M.; Templeton, J. L.; Meyer, T. J. Inorg. Chem. 2015, 54, 460.

(2) Norris, M. R.; Concepcion, J. J.; Glasson, C. R.; Fang, Z.; Lapides, A. M.; Ashford, D. L.; Templeton, J. L.; Meyer, T. J. Inorg Chem 2013, 52, 12492.

(3) Bettis, S. E.; Hanson, K.; Wang, L.; Gish, M. K.; Concepcion, J. J.; Fang, Z.; Meyer, T. J.; Papanikolas, J. M. J. Phys. Chem. A 2014, 118, 10301.

(4) Hanson, K.; Brennaman, M. K.; Ito, A.; Luo, H.; Song, W.; Parker, K. A.; Ghosh, R.; Norris, M. R.; Glasson, C. R. K.; Concepcion, J. J.; Lopez, R.; Meyer, T. J. J. Phys. Chem. C 2012, 116, 14837.

(5) Bard, A. J.; Faulkner, L. R. Electrochemical Methods: Fundamentals and Applications; Second ed.; John Wiley \& Sons, Inc.: New York, 2001.

(6) Juris, A.; Balzani, V.; Barigletti, F.; Campagna, S.; Belser, P.; Von Zelewsky, A. Coord. Chem. Rev. 1988, 84, 85.

(7) Hanson, K.; Torelli, D. A.; Vannucci, A. K.; Brennaman, M. K.; Luo, H.; Alibabaei, L.; Song, W.; Ashford, D. L.; Norris, M. R.; Glasson, C. R. K.; Concepcion, J. J.; Meyer, T. J. Angew. Chem. Int. Ed. 2012, 51, 12782.

(8) Rothenberger, G.; Fitzmaurice, D.; Grätzel, M. J. Phys. Chem. 1992, 96, 5983.

(9) Bettis, S. E.; Ryan, D. M.; Gish, M. K.; Alibabaei, L.; Meyer, T. J.; Waters, M. L.; Papanikolas, J. M. J. Phys. Chem. C 2014, 118, 6029.

(10) Grumstrup, E. M.; Cating, E. M.; Gabriel, M. M.; Pinion, C. W.; Christesen, J. D.; Kirschbrown, J. R.; Vallorz, E. L.; Cahoon, J. F.; Papanikolas, J. M. J. Phys. Chem. C 2014, 118,8626 .

(11) Trebino, R. Frequency-Resolved Optical Gating: The Measurement of Ultrashort Laser Pulses; Kluwer Academic: Boston, MA, 2000.

(12) Gaussian 09, Revision D.01; Frisch, M. J.; Trucks, G. W.; Schlegel, H. B.; Scuseria, G. E.; Robb, M. A.; Cheeseman, J. R.; Scalmani, G.; Barone, V.; Mennucci, B.; Petersson, G. A.; Nakatsuji, H.; Caricato, M.; Li, X.; Hratchian, H. P.; Izmaylov, A. F.; Bloino, J.; Zheng, G.; Sonnenberg, J. L.; Hada, M.; Ehara, M.; Toyota, K.; Fukuda, R.; Hasegawa, J.; Ishida, M.; Nakajima, T.; Honda, Y.; Kitao, O.; Nakai, H.; Vreven, T.; Montgomery, J. A., Jr.; Peralta, J. E.; Ogliaro, F.; Bearpark, M.; Heyd, J. J.; Brothers, E.; Kudin, K. N.; Staroverov, V. N.; Kobayashi, R.; Normand, J.; Raghavachari, K.; Rendell, A.; Burant, J. 
C.; Iyengar, S. S.; Tomasi, J.; Cossi, M.; Rega, N.; Millam, J. M.; Klene, M.; Knox, J. E.; Cross, J. B.; Bakken, V.; Adamo, C.; Jaramillo, J.; Gomperts, R.; Stratmann, R. E.; Yazyev, O.; Austin, A. J.; Cammi, R.; Pomelli, C.; Ochterski, J. W.; Martin, R. L.; Morokuma, K.; Zakrzewski, V. G.; Voth, G. A.; Salvador, P.; Dannenberg, J. J.; Dapprich, S.; Daniels, A. D.; Farkas, Ö.; Foresman, J. B.; Ortiz, J. V.; Cioslowski, J.; Fox, D. J.; Gaussian, Inc., Wallingford CT, 2009.

(13) Knight, T. E.; Goldstein, A. P.; Brennaman, M. K.; Cardolaccia, T.; Pandya, A.; DeSimone, J. M.; Meyer, T. J. J. Phys. Chem. B 2010, 115, 64.

(14) Mabrouk, P. A.; Wrighton, M. S. Inorg. Chem. 1986, 25, 526.

(15) Fitzmaurice, D. Sol. Energy Mater. Sol. Cells 1994, 32, 289.

(16) Lyon, L. A.; Hupp, J. T. J. Phys. Chem. B 1999, 103, 4623.

(17) Swierk, J. R.; McCool, N. S.; Saunders, T. P.; Barber, G. D.; Mallouk, T. E. J. Am. Soc. Chem. 2014, 136, 10974.

(18) Bertoluzzi, L.; Herraiz-Cardona, I.; Gottesman, R.; Zaban, A.; Bisquert, J. J. Phys. Chem. Lett. 2014, 5, 689.

(19) Houston, P. L. Chemical Kinetics and Reaction Dynamics; Dover Publications, Inc.: New York, 2006. 